\title{
Apontamentos sobre a ideologia da estética em Terra Sonâmbula (ou em nós, seus analistas).
}

\author{
Emiliano Augusto ${ }^{1}$
}

\begin{abstract}
RESUMO: O presente artigo procura fazer alguns apontamentos sobre ideologia da estética no romance moçambicano Terra Sonâmbula, do escritor Mia Couto, a partir das funções que exercem os cadernos de Kindzu na obra. Haverá considerações tanto sobre o porquê isso acontece neste romance quanto na linha em que o pesquisador se insere.
\end{abstract}

ABSTRACT: This article seeks to present some notes on the ideology of the aesthetics present in Mozambican novel Terra Sonâmbula, written by Mia Couto, analyzing the role of Kindzu's notebooks in the work. There are some thoughts on how it happens in this novel, as well as in the approach in which the researcher inserts himself.

PALAVRAS-CHAVE: Romance; Mia Couto; Ideologia da estética; Marxismo. KEYWORDS: Novel; Mia Couto; Ideology of the Aesthetic; Marxism.

Como disse Moizeis Sobreira (2010) em sua comunicação pronunciada no X Encontro de Estudos Comparados de Literaturas de Língua Portuguesa, o romance nasceu e tem se difundido sob o signo da instabilidade. Não é de surpreender, portanto, que a análise materialista dialética se concentre nas contradições que causam e que são causadas por esta instabilidade característica. Há muitos pontos de partida, e um dos mais comuns é a figura do herói, que é, sabemos, depositário de valores de classe. Mas a forma traz não só o herói que tenta construir-se, formar-se. Há outros valores, outras contradições, outros conteúdos históricos e sociais ali sedimentados, e o autor do presente artigo gostaria de sugerir uma análise a partir de outra contradição: a forma do romance traz em seu bojo também o dilema da

1 Mestrando do programa de Estudos Comparados de Literaturas de Língua Portuguesa da Universidade de São Paulo. Contato: emil.sofista@gmail.com. 
separação radical dos diversos campos da vida, e por causa disso o dilema da isolação em si mesma. Que quer dizer esta afirmação? Numa sociedade caracterizada pela separação e especialização de todas as funções, também o campo da arte, o campo estético, é um campo que pressupõe práticas e atividades especializadas, inserido que está nas relações de mercado e na divisão social do trabalho. Este artigo parte do pressuposto que mesmo a análise materialista tem, por vezes, ignorado esta contradição, e tenta fornecer algumas explicações do porquê, não refutando esta linha de pensamento, mas inserido nela, ora defendendo-a, ora fazendo autocrítica. Como fio condutor, a análise de que maneiras a separação do e o isolamento no estético se dão no romance Terra Sonâmbula, de Mia Couto.

A análise de obras escritas durante ou no entorno das lutas de libertação ou de guerra civil das antigas colônias portuguesas em África - inseridas nestes contextos e, portanto, sempre tomando posição sobre o que acontece no momento - que consiga imbricar conteúdos sociais e aspectos formais com frequência chegará a conclusões importantes sobre as pressões que a forma literária sofre nesses contextos. Os marxistas procuramos sempre, e nos regojizamos quando encontramos, indícios de superação da arte burguesa, ou ao menos marcas que a luta de classes imprimiu na forma. A narrativa repartida entre a luta de Tuahir e Muidinga para sobreviver e as buscas de Kindzu certamente seria chão fecundo para este tipo de análise, mas este artigo partirá de um ponto que parece mais espinhoso, porque não inteiramente resolvido, tanto para a nossa linha crítica quanto para o romance de Mia Couto. Então, ao invés daí, a análise partirá das funções exercidas pelo ponto que serve de contato entre as duas narrativas, os cadernos de Kindzu.

A primeira coisa a ser levantada é que o próprio Kindzu não parece saber a que propósito escrever serve. Assim, temos no último caderno:

Ou fazer como minha mãe me ensinou: ser a mais delicada sombra. É isso que desejo: me apagar, perder voz, desexistir. Ainda bem que escrevi, passo por passo, 
esta minha viagem. Assim escritas estas lembranças ficam presas no papel, bem longe de mim. Este é o último caderno. (COUTO, 2007, p. 200.)

Que se pode contrastar com o seguinte trecho do décimo caderno: quê?

- O que andas a fazer com um caderno, escreves o

- Nem sei, pai. Escrevo conforme vou sonhando.

- E alguém vai ler isso?

- Talvez.

- É bom assim: ensinar alguém a sonhar. (COUTO, p. 182.)

Cabem algumas considerações. Há sempre uma ambiguidade a tensionar o primeiro sentido dessas linhas. No trecho do último caderno, é um Kindzu exausto e desiludido quem escreve. Suas buscas até ali se revelaram infrutiferas, e ele presenciou mais desgraças e sofreu mais derrotas que os ombros podem aguentar. Num momento de fraqueza, são as três negativas antes do cantar do galo. No segundo trecho, temos uma função dada aos cadernos. O sonhar ali pode ser o onírico, mas também pode ser o chamado a manter a utopia no horizonte. Dada a conjuntura, nosso primeiro impulso é argumentar em favor do segundo. Mas é necessário lembrar que quem dá esta função aos cadernos é um personagem nem um pouco confiável: o fantasma insano que persegue Kindzu, seu pai. O trecho ensaia uma reconciliação entre o filho e o pai, mas se ela se cumpre aqui, fica em aberto, porque o sonho é interrompido. Assim, para Kindzu, a resposta da pergunta - Que farei eu com este livro? - demora a ficar clara.

Se para o escrevinhador dos cadernos a situação demora a clarear, para nós, leitores, a conclusão não é dificil. Primeiro, num plano mais formal, como dito acima, os cadernos são o ponto de contato entre as duas narrativas. Se Muidinga é Gaspar ou Vinticinco de Junho, fica em aberto; é possível pensar inclusive que não seja nenhum dos dois, e no fim isso importa menos que os cadernos. Sem o caderno, teríamos apenas duas narrativas desconectas: as buscas frustradas de Kindzu de um lado, o ônibus e os para sempre perdidos Tuahir e 
Muidinga de outro, dois retratos de uma terra que nunca se cumpre. Já pensando na imbricação com o conteúdo, é só através dos cadernos que a busca tem fim e que os perdidos podem reabilitar-se.

Nos cadernos, Kindzu deposita as lendas, parte da tradição oral de Moçambique, que conhecera em suas andanças. Deposita também as esperanças, preocupações, histórias e estórias da geração que lutou e morreu nas guerras de libertação e na guerra civil que assolou o país a seguir. E é através desse conhecimento depositado nos cadernos que a geração mais nova, representada na figura de Muidinga, e a geração mais velha, representada na figura de Tuahir, podem ligar-se e realizar a sintese entre a cultura oral e a escrita. É com esta síntese que Muidinga consolará e alentará o último sono de Tuahir no mar, é esta síntese que está contida nas páginas que se tornarão a terra de Moçambique.

Mais ainda, os cadernos são o último foco de resistência. Eles contém as premonições e avisos do feiticeiro sobre a guerra e seus motivos:

Porque esta guerra não foi feita para vos tirar do país mas para tirar o país de dentro de vós. Agora, a arma é a vossa única alma. Roubaram-vos tanto que nem sequer os sonhos são vossos, nada de vossa terra vos pertence, e até o céu e o mar serão propriedade de estranhos. (COUTO, p. 201)

Desencobre-se o processo: a administração colonial pode ter acabado, mas a espoliação continua, agora através da globalização. O colonizador volta da catacumba, e se antes ao menos o inimigo era declarado, agora a face do sistema está terceirizada, ocupa o cargo um moçambicano. Mas, como os cadernos nos avisam, também por eles se pode lutar:

o colono Romão Pinto junto com o administrador Estêvão, Shetani, Assane, Antoninho e milicianos. Vinham armados e se dirigiram para Junhito, com ganas de lhe depenar o pescoço. Cercaram o manito, dizendo:

- Teu pai tinha razão: sempre te viemos buscar.

Então, Junhito me chamou. Eu me olhei, sem confiança. Mas o que em mim vi foi de dar surpresa, mesmo em sonho: porque em meus braços se exibiam lenços e 
enfeites. Minhas mãos seguravam uma zagaia. Me certifiquei: eu era um naparama! Ao me verem, em minha nova figura, aqueles que maltratavam o meu Irmão se extinguiram num fechar de olhos. (COUTO, p. 203)

E por fim, os cadernos permitem a reconciliação com o pai e a conciliação das buscas de Kindzu:

Uma voz interior me pede para que não pare. É a voz de meu pai que me dá força. Venço o torpor e prossigo ao longo da estrada. Mais adiante segue um miúdo com passo lento. Nas suas mãos estão papéis que me parecem familiares. Me aproximo e, com sobressalto, confirmo: são os meus cadernos. Então, com o peito sufocado, chamo: Gaspar! E o menino estremece como se nascesse por uma segunda vez. (COUTO, p. 204)

De uma feita, Kindzu termina sua busca pelos naparamas, por Junhito e por Gaspar. Ensinando outros a sonhar e, portanto, a resistir e lutar, o herói restaura o sentido do Vinte e Cinco de Junho, a data da Libertação de Moçambique. Como dissemos acima, é através da leitura dos cadernos que Muidinga pode ser completamente reabilitado. Mesmo que originalmente ele não fosse Gaspar, Kindzu lhe entrega uma história. É uma bela metáfora do que esperamos da literatura. E justamente aí reside o problema: quando se espera que a obra de arte, pelo poder que ela tem de causar reação (e ainda mais grave quando se espera que será pelas suas qualidades estéticas intrínsecas), seja aquilo que levará ao cumprimento de todas as promessas de reconciliação, e a principal arma e meio com qual a luta será lutada e onde a luta se dará.

Claro, não é a toa que depositamos tanta esperança neste campo:

Historicamente [...] a definição de reação estética é uma afirmação, diretamente comparável com a definição e afirmação da "imaginação criativa", de certos significados e valores humanos que um sistema social dominante reduziu e mesmo tentou excluir. Sua história é, em grande parte, um protesto contra a transformação forçada de toda a experiência em instrumentalidade ("utilidade") e de todas as coisas em mercadorias. (WILLIAMS, 1979, p. 151.) 
As contradições deste tipo de reação nos levam a uma situação real bastante complexa, principalmente quando se percebe que "a forma desse protesto, dentro de condições sociais e históricas definidas, levou quase que inevitavelmente a novos tipos de instrumentalidade privilegiada e de mercadoria especializada. A reação humana, não obstante, estava presente" (WILLIAMS, p. 151). De fato, mesmo a crítica de matiz mais materialista e marxista, principalmente porque calcada nessa possibilidade de reação daquilo que é humano, por muito tempo deixou de perceber - e constantemente tem deixado - os problemas que surgem quando se opera considerando-se o campo estético completamente apartado de todas as outras esferas da vida humana.

Para entender os problemas que esta separação causa, seguiremos a análise crítica que Raymond Williams faz das definições lukácsianas. Diz o autor:

Lukács procurou definir a arte de um modo que a distinguisse, categoricamente, do "prático" e do "mágico". Prático, no caso, é limitado pela contenção dentro de formas históricas específicas. Por exemplo, a prática reduzida da sociedade capitalista, que é ordinariamente reificada como "realidade" e para a qual a arte é então alternativa necessária. (p. 151)

Ficam claros neste trecho tanto a tentação para a teoria marxista, quanto o porquê de termos nos rendido no passado e continuarmos a nos render a tal tentação no presente. Em momentos em que as estruturas de poder se tornam mais totais, capazes de desarmar e desmoralizar a maior parte de seus antagonistas (EAGLETON, 1990, p. 381.), em que o capital sujeita a maior parte das áreas da vida humana a si, é alentador que haja um front de onde se possa resistir. Mas, para começar a considerar os problemas desta proposição, temos que analisar também no que, para Lukács, segundo Williams, a arte se distingue do mágico e do religioso: "Estes oferecem suas imagens como crença objetivamente real, transcendente, exigente. A arte oferece suas imagens como imagens, fechadas e reais em si mesmas (seguindo um isolamento familiar do 'estético')" (WILLIAMS, p. 152). 
Este isolamento combinado com uma realidade que se basta por si é chave para que se entenda o problema. Recorramos à fábula weberiana proposta por Eagleton (p. 366), e imaginemos uma sociedade pré-capitalista em que as três grandes questões da filosofia - "what can we know? what ought we to do? what do we find attractive" - ainda não podiam ser inteiramente distinguiveis umas das outras: "a society, that is to say, where the three mighty regions of the cognitive, the ethicopolitcal and the libidinal-aesthetic were still to a large extent intermeshed." Assim:

\begin{abstract}
Knowledge was still constrained by certain moral imperatives - there were certain things you weren't supposed to know - and was not viewed as sheerly instrumental. The ethico-political question [...] was not regarded simply as a matter of intuition or existential decision or inexplicable preference, but involved rigorous knowledge of what we were, of the structure of our social life [...]. Art was not sharply separated from the ethicopolitical, but was one of its primary media; and it was not easily distinguishable from the cognitive either, because it could be seen as a form of social knowledge, conducted within certain normative ethical frameworks. It had cognitive functions and ethico-political effects. (EAGLETON, p. 366. grifos meus.)
\end{abstract}

O texto de Eagleton faz um movimento interessante aqui, brincando com as expectativas do leitor. Mais à frente, o autor desmanchará essa expectativa que ele vinha alimentando: "This history may seem yet another ritual of nostalgic remembrance for the organic society, but in fact is not. For why should we presume that the condition in which these three discourses were intermeshed was a positive one?" (p. 367), dirá ele, e em seguida elencará algumas vantagens que a separação radical desses campos trouxe, como a ciência se tornando "a revolutionary strike against the statesman and high priests in the name of human welfare and intellectual independence"; a preocupação ética se libertando do aparato eclesiástico e seu escopo estreito, e tornando-se livre para preocupar-se com questões de justiça e dignidade humanas; e, a parte que mais 
interessa a este trabalho, a arte deixando de ser mera lacaia do poder político (p. 367). Deixemos isto de lado momentaneamente, e voltemos ao trecho grifado. Trecho que nos diz por que esta nostalgia pode ser tão tentadora: aponta para uma noção de arte altamente orgânica, que nascendo no seio da sociedade pode ser usada ao mesmo tempo para entendê-la e para ajudar a modificá-la; ou, ao menos, ajudar a organizar a luta para modificá-la. Claro, visão por um lado ingênua, por outro ideológica em ignorar isso que Eagleton quer nos lembrar: apesar de todas as contradições que envolvem a separação destes campos, algumas vantagens há, e a maior delas, no que diz respeito à arte, é a possibilidade dela deixar de ser simples reflexo ou acessório de um poder político central e absoluto.

Mas vamos às contradições:

Art is now autonomous of the cognitive, ethical and political; but the way it came to be so is paradoxical. It became autonomous of them, curiously enough, by being integrated into the capitalist mode of production. When art becomes a commodity, it is released from its traditional social functions within church, court and state into the anonymous freedom of the market place. [...] It is 'independent' because it has been swallowed up by commodity production. (EAGLETON, p. 368. Itálico do autor)

Esta independência inteiramente integrada e, portanto, dependente do modo de produção industrial capitalista, é fonte de um dilema não superado, tanto em artistas quanto em analistas, desde que se inaugura a Modernidade; as discussões sobre o papel da arte, a liberdade artística, e o que é ou não é arte geralmente passam por este ponto, quase sempre de maneira repetitiva e estéril. A discussão iniciase provavelmente com Kant distinguindo a arte livre da arte mercenária (o leitor mais versado poderá nos corrigir-auxiliar com um exemplo anterior), e arrasta-se até os dias de hoje, e, claro, ganha sobrevida muitas vezes ignorando essa contradição apontada pela dialética materialista (ou porque muitas vezes os próprios marxistas a ignoramos). A distinção que se faz, por exemplo, entre a alta cultura, ou 
a verdadeira cultura, e a cultura de massas (termos, que, como nos ensina Raymond Williams, são altamente ideológicos porque encobrem os modos pelos quais a produção cultural está integrada ao modo de produção industrial. Por isto, o autor prefere Indústria Cultural) é um dos desdobramentos desta contradição.

Claro, não só por ignorância o dilema em torno de uma contradição, nem sempre percebida, persiste (às vezes gostamos de dar ares de panaceia ao nosso método). No prefácio de 1962 à Teoria do Romance, Lukács acaba por sugerir a rejeição categórica desta obra. Mas há algo ali que não podemos deixar morrer, apesar do idealismo utópico radical (defensável naquele momento), apontado pelo próprio autor e por Williams, entre outros, apesar da separação radical e isolamento da arte e do estético (problema a que voltaremos logo mais) que é uma noção da sedimentação de conteúdos sociais na forma.

O formalismo também trabalha de maneira a aproximar forma e conteúdo. Cleanth Brooks, crítico do formalismo de lingua inglesa, por exemplo, propõe que "in a successful work, form and content cannot be separated", e que "form is meaning"(2001, p. 1366). Isso é verdade, e pode ser expandido inclusive para obras que o critico formalista ou o terrivel juiz do mercado considerem fracassos. A vantagem de um método materialista-histórico dialético é a percepção de que a forma não é simplesmente uma arbitrariedade do autor, mas resultado de diferentes anseios e conflitos não só do autor, mas da sociedade que a produz e ou utiliza. A forma também é palco das lutas de classes, e mesmo os conteúdos que estão historicamente sedimentados nela são sempre alvo de pressão e mudança. Assim, por exemplo, podemos ver na narrativa dividida de Terra Sonâmbula um indice da guerra civil que assolou Moçambique após as lutas de independência, e uma solução formal que dá conta da sociedade tão partida naquele momento.

Além do mais, este artigo quer trabalhar com a hipótese de o problema de a separação dos campos e o isolamento da arte e do estético estarem presentes na forma das artes que sobrevivem à entrada na Era Moderna (como a pintura, a literatura, as artes dramáticas), ou 
mesmo das que surgiram após a hegemonia do modo de produção capitalista, mas que surgem ainda muito inspiradas, por assim dizer, nestas artes que sofrem com o dilema desta independência dependente (como a fotografia e o cinema).

Voltemos ao problema dessa independência integrada ao modo de produção. Tomada de assalto por esta contradição (bem como pelas novas configurações da sociedade, que empurram a arte para fora da sua antiga relevância: "Marx reminds us that the bourgeoisie have absolutely no time for it"(Eagleton, p. 368)), a arte reage, oferecendo como solução o isolamento do e no campo estético:

Though artistic production itself play less and less of a significant role in the social order [...], what it is able to benequeath to that order, as it were, is a certain ideological model which may help it out of its mess - the mess which has marginalized pleasure and the body, reified reason, and struck morality empty. The aesthetic offers to reverse this division of labour, to bring these three alienated regions back into touch with one another, but the price it demands for this generosity is high: it offers to interrelate these discourses by effectively swallowing up the other two. Everything now should become aesthetic. (Eagleton, p. 368)

À esquerda e à direita, sabemos onde isso vai dar. Sobre o lado de lá, conhecemos o ensaio de Benjamin (1994), a respeito do fascismo e a estetização da guerra, a substituição operada pelo Terceiro Reich de um projeto político por um projeto estético. "It all begins in the work of art, and ends up with a scarecrow in a field" (Eagleton, p. 369). Do lado de cá, há uma longa linha que começa com um utopismo positivo, da arte como crítica da alienação, como exemplo de realização criativa das energias produtivas humanas, como o campo da reconciliação do sujeito e do objeto, do indivíduo e da sociedade; passando pelo momento em que "the aesthetic becomes the guerilla tactics of the secret subversion, of the silent resistance [...]. Art will pulverize traditional form and meaning, because the laws of syntax and grammar are the laws of police" (Eagleton, p. 369); até o momento em que, 
cansados de ver a arte absorvida pelo mercado e pelo capital, o Picasso pendurado na parede do banco (Eagleton, p. 372), passamos a nos focar na arte que se consome no momento de sua realização, ou em outras maneiras de resistir à incorporação cada vez mais veloz. O problema, na verdade, é sempre nos deixarmos levar pela isolação do artístico e do estético em si mesmo: "How idealist to imagine that art, all by itself, could resist incorporation" (Eagleton, p. 372. Itálico do autor.). O problema da incorporação não é um problema estético ou artístico; é um problema político: "The one thing which the bourgeoisie cannot incorporate is its own political defeat" (Eagleton, p. 372). Mas por vezes, nós, como analistas e críticos, tão envoltos estamos com a nossa atividade e com o nosso objeto de estudo, não percebemos isto. E é tentador imaginar que esta leitura de Mia Couto, se bem feita, irá abalar as estruturas do capitalismo global. Não irá, e a potência lírica de Terra Sonâmbula, que de um lado nega a reificação de todas as coisas e, portanto, a sua própria, e de outro afirma uma posição que aponta para a superação disso, não impedirá que eventualmente ouçamos citações do romance em propagandas de multinacionais que desejam se expandir nas costas índicas.

Mas, se esperamos tanto assim de um trabalho crítico, e mais tanto de um trabalho literário, isso nos diz bastante sobre o momento em que vivemos. Se o movimento é colocar todas as fichas numa única aposta, é porque esta é a única aposta que parece possivel e segura. Não é de se estranhar que a única arma que reste a Kindzu sejam seus cadernos. Pelo contrário, é compreensível. A guerra civil e a corrupção generalizada que assolaram Moçambique de um lado, e a falência do projeto socialista de outro, são derrotas duríssimas e desmobilizadoras. Uma coisa é lutar sempre pela liberdade que nunca vem. Outra completamente diferente e ainda mais grave é chegar tão próximo daquele projeto utópico e percebê-lo esfacelar-se nas mãos, em parte destruído por aqueles que prometeram ajudar a realizá-lo. Neste momento, o recolhimento, o passo atrás, novos lugares de resistência são necessários e bem-vindos, e por si, o estético não é deletério. A 
armadilha nos prende quando ignoramos a contradição: este campo é também um campo inserido na divisão social do trabalho, e pode operar com práticas altamente especializadas, tanto de escrita quanto de leitura. E enquanto a contradição for ignorada, os sonhos dos cadernos de Kindzu não se realizarão.

\section{Referências Bibliográficas}

BENJAMIN, Walter. "A obra de arte na era de sua reprodutibilidade técnica". Obras Escolhidas I: Magia e Técnica, Arte e Política. São Paulo: Brasiliense. 7. ed.,1994.

BROOKS, Cleanth. The Formalist Critics. In: LEITCH, Vincent B. (ed.) The Norton Anthology Of Theory And Criticism. New York London: W.W. Norton \& Company, 2001, p. 1366-1371.

COUTO, Mia. Terra Sonâmbula. São Paulo: Cia das Letras, 2007.

EAGLETON, Terry. From the Polis to Postmodernism. In: The Ideology of the Aesthetic. Cambridge: Basil Blackwell, 1990, p. 366417.

KANT, Immanuel. From Critique of Judgment. In: The Norton Anthology Of Theory And Criticism. New York - London: W.W. Norton \& Company, 2001, p. 504- 535.

LUKÁCS, Georg. A Teoria do Romance. MACEDO, José Marcos Mariani de (trad.). São Paulo: Duas Cidades/Editora 34. $1^{\text {a }}$ ed., 2000.

SOBREIRA, Moizeis. Entre o indivíduo e o Coletivo: o herói de Mayombe. Comunicação apresentada no X Encontro Encontro de Estudos Comparados de Literaturas de Lingua Portuguesa: Literatura e Vida Social. São Paulo, 2010. 
WILLIAMS, Raymond. Marxismo e Literatura. DUTRA, Waltensir (trad.). Rio de Janeiro: Zahar Editores, 1979. 